Open Access

\title{
On the origin of innovations-the opportunity vacuum as a conceptual model for the explanation of innovation
}

Patrick Planing(D)

Correspondence:

mail@patrickplaning.com

Business School, Pforzheim

University, Pforzheim, Germany

\begin{abstract}
The aim of this paper is to transfer the innovation system (IS) approach to the microeconomic level, creating a conceptual framework which helps individual actors to explain, identify, and predict the origin of innovations. Based on the ongoing discussion about the applicability of boundedly rational search and, in particular, the metaphor of an opportunity landscape, the author has developed a conceptual framework for the origin of economic innovations, structured along three dimensions. First, the adjacent possible defines a narrow space of potential first-order combinations of exiting knowledge, which is the trajectory for the new developments in technology and science. Second, the adjacent feasible defines an area of expected cost reduction which enables the exploitation of the new technologies within a threshold. Finally, the adjacent acceptable represents a small area on the current edges of socially accepted behavior, which currently only innovators embrace, but soon will reach the early majority of adopters. It is, however, the moment when all three dimensions achieve an intersecting area, when the opportunity vacuum (OV) is created. The OV is a space, which strongly attracts innovation and often creates multiple inventions at the same time emerging independently. While this model is aimed at explaining the origin of economic innovations in retrospective, it can also be applied as a framing method to anticipate future economic novelty.
\end{abstract}

Keywords: Innovation, Origins, Opportunity mapping, Adjacent possible, Entrepreneurship

\section{Background}

The development and exploitation of breakthrough ideas, concepts, and technologies, generally referred to as innovation, is the driver of human advancement and prosperity. Given this importance, surprisingly little research has been conducted on the origin of innovations.

Recently, however, the origins of economic opportunities have received significant attention in entrepreneurship, organization science, and strategy. The first conceptual models for the emergence of innovations implied a linear innovation process. In this linear view, science leads to new technologies, which in the next stage satisfy market needs (Edquist and Hommen 1999). The omission of feedback loops from the several later stages of the innovation process, e.g. market and consumers, toward the earlier

(c) The Author(s). 2017 Open Access This article is distributed under the terms of the Creative Commons Attribution 4.0 International License (http://creativecommons.org/licenses/by/4.0/), which permits unrestricted use, distribution, and reproduction in any medium, provided you give appropriate credit to the original author(s) and the source, provide a link to the Creative Commons license, and indicate if changes were made. 
stages led to criticism on a pure linear, sequential view of innovation. Kline and Rosenberg (1986) consequently proposed the chain-linked model, where the process of innovation could also be initiated by the identification of an unfilled market need instead of a new scientific insight. They also introduced the notion of complex feedback loops between organizations and the scientific community in order to fill knowledge gaps. Over the last decades, the tradition of innovation studies was developed further (e.g. Freeman 1987 and Lundvall 1992) and increasingly integrated with scholars of evolutionary theories (e.g. Nelson and Winter 1982 and Metcalfe 1988). This eventually led to the development of the innovation system (IS) approach. The central idea behind this theory is the notion that what appears as innovation at the macro level is in reality the result of an interactive process that involves many different actors at the micro level. In this view, the innovation system is a continuous process where habits and practices of institutions, as well as networks, play a central role in generating innovation and technological change. This interplay of different actors in generating novel knowledge was first described by Etzkowitz and Leydesdorff (2000) in their "Triple Helix" model. By establishing the idea of trilateral networks between research, industries, and government, this model emphasized the coexistence and coevolution of different knowledge sources. More recently, the idea of a Quadruple and Quintuple Helix emerged (see Carayannis and Campbell 2009; Carayannis et al. 2012). The Quadruple Helix model is based on the Triple Helix model and adds as fourth helix the "public", which is defined as the "media-based and culture-based public" and civil society. The Quintuple model adds as fifth helix the "natural environment". The use of the IS framework and the "Helix" models of knowledge generation, however, have a major limitation. The explanatory power of the frameworks is focused on the macro level, addressing the role of institutions and less the actions of the individual entrepreneurs and inventors acting on the micro level (Hekkert et al. 2007).

The aim of this paper is to transfer the innovation system (IS) approach to the microeconomic level, creating a conceptual framework, which helps individual actors to identify and predict economic opportunities. The application of network systems and evolutionary theory to microeconomic activity has so far been conducted mostly from a technology perspective. One of the most discussed models in this context is opportunity mapping, which uses landscape cartography as metaphor for explaining the emergence of innovation. The origins of this concept can be traced back to theoretical and evolutionary biology (see Kauffman and Levin 1987) and consequently found its way into organizational theory and lately opportunity recognition in entrepreneurship literature (Felin et al. 2014). The concept of an opportunity landscape, however, has recently been challenged, particularly in the context of explaining the emergence of economic novelties. Winter (2012) argues that "serendipity" and surrounding circumstances are the decisive factors for the origin of innovations. Also, there is an ongoing debate whether economic opportunities can really be discovered or whether they are rather created as part of the progress (Alvarez et al. 2013; Eckhardt and Shane 2013). In their recent publication, Felin et al. (2014) argue that the computational algorithms, such as NK modeling, are not suitable methods for explaining the origins of economic novelty.

In sum, there is a convincing argument that a computational approach for predicting future entrepreneurial activity on the microeconomic level is not practicable. Nonetheless, the phase space where novel entrepreneurial activity happens is a scientifically explicable in nature. Defining this space, however, should not be considered an 
algorithm problem but rather a framing problem. Felin et al. (2014) recommend that emerging innovations are best captured by focusing more carefully on the endogenous nature of organisms, including economic actors, and by focusing on the constraints that enable the occurrence of future innovations.

In this line of reasoning, the overall contribution of this paper is to transfer the innovation system (IS) approach to the micro level and develop a conceptual model for the framing of microeconomic opportunities along the constraints of economic and social development. The model is aimed at providing an explanation for the emergence of innovation in retrospective but will also provide a framework for the search of future entrepreneurial activity.

\section{Theoretical framework}

\section{Definition of innovation}

So far, the academic discussion is still some way from reaching a common agreement on the definition of innovation (see White and Bruton 2011; Kaplan and Warren 2010; Berkun 2010; Baregheh et al. 2009; Adams et al. 2006). Reviewing different definitions for innovation, it becomes obvious that a new idea by itself is not yet an innovation; it could merely be regarded as a concept or a thought. The process of converting these thoughts into tangible new artifacts (a product, a service, or a process) is usually called invention. The later activities that lead to an invention becoming a success in the marketplace or in a society as a whole represent exploitation. It is, however, the complete process that represents innovation (Trott 2010; Baregheh et al. 2009). While there are many differences in the description of the innovation process, the common denominator is that it consists of an idea, the realization or invention and the exploitation. Thus, in a simplified version, the definition of innovation reads as follows:

$$
\text { Idea }+ \text { Invention } / \text { Realization }+ \text { Exploitation }=\text { Innovation } .
$$

Next to the definition of innovation, there is also an ongoing discussion about the typology of innovations. While no common agreement exist, scholars regularly categorize innovations by their degree of newness. Dichotomous categorizations range from non-drastic to drastic (Arrow 1962), incremental to radical (Freeman 1994), or sustaining to disruptive (Christensen 1997). In recent years, more fine-grained and multi-layered typologies have been developed (Coccia 2005). These typologies take into consideration that newness has to be defined from a technology, business, and customer perspective (Zawislak et al. 2011). Innovations can have a varying degree of newness on each level of analysis. What is a fundamentally new technology, for instance, might not be perceived as new by customers (e.g. plasma TVs and LCD TVs). An incrementally changed product, on the contrary, might be perceived as radical new to customers if it requires a behavior change. In order to derive a holistic model for the origin of innovations, it is consequently necessary to consider the ideation, realization, and exploitation part of innovation as well as the technological, economic, and customer dimension of innovation. This defines the scope of analysis for developing a conceptual model in the next step. 
The macro level: origin of innovations in innovation systems

The innovation system (IS) framework focuses on to the role of policy intervention in relation to the changes in innovation behavior (Iizuka 2013). Its research object is the process of innovation on a macroeconomic level, which involves the implementation of new ideas to achieve desired social and economic outcomes (Hall 2005). In the IS framework, a new product or process is considered implemented when it is introduced to the market. The emphasis on introduced to the market puts the firms' activities and their interrelation at the heart of the innovation process (Gault 2012). Understanding the origin of innovations in an IS framework therefore requires knowing how ideas, skills, and knowledge are transferred, diffused, and acquired throughout the system. In its basic formulation, the implementation of a new idea requires a prior learning process, which can be stimulated either by research (STI mode) or by users putting knowledge into practice (UDI mode) (Iizuka 2013; Lundvall 2007). The research (STI mode) can be observed by the $R \& D$ expenditure (input) and patenting activities (output), while the user-driven innovation (UDI) mode requires more refined methods of inquiry, including an analysis of the role of informal networks and general knowledge flow among users (Tacer and Ruzzier 2015). One such method is the Quadruple Helix System of innovation (Carayannis and Campbell 2009), which was recently introduced as an analytical framework that synthesizes the key features of stakeholder interactions into an "innovation system" format, defined according to the systems theory as a set of components, relationships, and functions (Ranga and Etzkowitz 2013). The model postulates that the overall function of innovation systems-knowledge and innovation generation, diffusion and use-is realized through a set of activities in the knowledge, innovation, and consensus spaces. The non-linear interactions between the spaces can generate new combinations of knowledge and resources that can advance innovation theory and practice. Thus, the IS framework and its application in Quadruple and Quintuple Helix Systems can help to identify network knowledge flows by analyzing the interactions among stakeholders on a macro level. From this perspective, the origin of innovations is explained as a constellation of collective learning. How individual ideas are created on the micro level, however, cannot be explained by this framework.

The micro level: origin of innovations by individual actors

From a micro perspective, the functions of innovation systems-knowledge and innovation generation, diffusion, and use-need to be analyzed by considering individual actors as research objects. The creation of ideas by individuals was long attributed to either genius or serendipity - a lucky moment finding a valuable insight without actually looking for it (Roberts 1989). More recently, however, human creativity was demystified. Empirical research shows that the development of novel ideas has less to do with the inexplicable genius of some individuals than with circumstances in which they occur (see Csikszentmihalyi 2014; Boden 2004). In a broader sense, we now know that new ideas are based on the combination and reorganization of exiting knowledge. If we accept that new ideas are based on exiting knowledge, then there is a natural boundary of how far new ideas might go. No genius of any sort could have invented an iPhone in 1850, since the technological trajectory was not anywhere near this point at that time. If there is a "natural limit" to innovation, then how can we describe the field of possible innovations? 
If innovation would be a natural science, researchers would try to come up with a formula defining the boundaries of innovations. While there is an ongoing discussion whether this is theoretically possible for economic activities, attempts to explain the field of possible innovation have recently emerged from a totally different discipline-theoretical biology.

\section{Applying evolutionary theory to the origin of innovations}

Theoretical biologist Stuart Kauffmann introduced the theoretical perspective of the "adjacent possible" (Kauffman 2002), which consequently found its way into complexity theories of organizations (Mitleton-Kelly 2003) and opportunity recognition in entrepreneurship literature (Felin et al. 2014). The original concept explains selection and novelty as a sequence how evolutionary niches get occupied by new species. The idea is that evolution always searches space for possibilities. Such possibilities are one step away from what already exists (Felin et al. 2014). Think of all those initial molecules in the primordial soup after the earth's creation and then imagine all the potential new combinations that they could form spontaneously, simply by colliding with each other (or perhaps supported by some extra energy of a lightning strike). If you could play God and trigger all those combinations, you would end up with most of the building blocks of life: such as proteins that form the boundaries of cells or sugar molecules, which are crucial to the nucleic acids of our DNA. But you would not be able to trigger chemical reactions that are necessary to build an elephant, a sunflower, or a human brain. Creating a sunflower, however, relies on a whole series of subsequent innovations: chloroplasts to capture the sun's energy, vascular tissues to circulate resources through the plant, DNA molecules to pass on instructions to the next generation (Johnson 2010).

Systems, may it be on the molecular, morphological, behavioral, technological, or organizational sphere, explore the adjacent possible while mutating their characteristics. If systems can adapt to such new spaces, they successfully find new ways of making a living (Mitleton-Kelly 2003). Immediate change is limited to options that are only one step (intellectual or biological) away. But once such changes are made, then new opportunities become adjacent (i.e. just one step away) and therefore possible. One way to illustrate this concept is to imagine a conceptual room that has an entrance and several possible exits, represented as doors that are ajar rather than closed. You can never jump many rooms ahead but are limited to progress one room at a time via the "adjacent possible".

The most important characteristic of the adjacent possible is that its boundaries grow as you explore them. Each new combination opens up the possibility of other new combinations. It is a conceptual sphere of knowledge that magically expands as you explore it. You begin by combining exiting hunches of knowledge, each leading to a new possibilities which have not been there before. By expanding the body of knowledge, the possibilities of combinations expand too; therefore, we develop away from chaos (entropy) and toward complexity and order (negative entropy). Throughout history, qualitative changes in technology have always been toward more complexity (Rifkin and Howard 1981). Comparing the intellectual capacity of humans to a random experiment of combinations, as it happens with molecules, seems far-fetched. Indeed is our brain capable of much more, especially building a coherent story out of individual hunches. On a basic neuronal level, 
it is, however, just that: making connections. Studying the properties of disruptive innovations, Goldberg et al. (2003) found that $85 \%$ of successful innovations are built on exiting ideas but modified by subtraction, division, merging, or multiplication. In contrast to molecular connections, thus, innovations can not only emerge by combinatory methods but also by modifying exiting technologies.

It has to be acknowledged that occasionally ideas are developed far out of the adjacent possible. One of the most known examples is certainly Leonardo da Vinci, who designed a working parachute in 1483, which was first realized in 1783 by Louis-Sébastien Lenormand, jumping from an observation tower in Montpellier. Another remarkable example is the first programmable computer conceptualized in theory by Charles Babbage in 1837, more than a century before it was possible to develop such a machine. These outstanding concepts and ideas have one thing in common-they cannot be considered an innovation. A great idea or concept is just that. Only be realizing the idea and exploiting or diffusing an idea into the society or a specific target group it becomes an innovation and thus a benefit to society.

\section{Proposed conceptual model-the opportunity vacuum}

In an attempt to describe the (physical) properties of the adjacent possible the closest parallel would be a vacuum. A vacuum, a space where there is little or no matter ("vacuum"). On earth, a vacuum is temporary in nature and quickly filled with matter once possible. The same is true for the space, which Stuart Kauffmann defined as the adjacent possible. It is uncharted space on the edges of current knowledge with nothing in it, yet the place where the new ideas emerge quickly. Within this sphere, innovation happens fast and so manifold that it is quite common to see multiple inventions at the same time emerging independently. This remarkable pattern was first investigated by the researchers William F. Ogburn and Dorothy Thomas in their 1922 paper Are Inventions Inevitable (Ogburn and Thomas 1922). Their paper listed 148 major inventions and discoveries that were made independently by two or more two or more groups at the same time. A similar study by Merton in 1961 led him to conclude that "the pattern of independent multiple discoveries in science is in principle the dominant pattern, rather than a subsidiary one" (Merton 1961 p.470). Today, there is even continuously expanding Wikipedia list of multiple inventions ("list of multiple discoveries"). Examples include the atomic bomb, the jet engine, cosmic background radiation, and quantum cryptography-just to name a few.

Since the adjacent possible defines a narrow space of potential first-order combinations of exiting knowledge, it is not a coincident that new ideas emerge within these boundaries. This phase sphere is the breading ground of new ideas. It is where innovation almost magically emerges in great number and often do so at the same time yet independent from each other. Regarding the emergence of new ideas alone, however, does miss the important constraints of innovation. Considering the definition of innovation, developed in the first passage, there are three distinctive components of an innovation: the idea, the realization, and the exploitation. Each component is a prerequisite for innovation success, so the breakthrough of an innovation can be stalled or spurred by either one. Take the invention of the light bulb as a classic example. In 1840, British scientist Warren de la Rue developed an efficiently designed light bulb using a coiled platinum filament in place of copper, but the high cost of platinum kept 
the bulb from becoming a commercial success. Around 40 years later, American inventor Thomas Edison developed a cheaper and more durable version and is ever since credited as the inventor of the light bulb. Consequently, the viability of a technology as well as the successful diffusion of a technology within a society is an equally important factor for successful innovation than the idea creation. Consequently, the true breading ground of innovation, which will further be referred to as the opportunity vacuum (OV) has three dimensions which can be thought of as layers stacked on each other's. The three dimensions of the OV are the following:

1. The Adjacent Possible (Technology)

2. The Adjacent Viable (Economy)

3. The Adjacent Acceptable (Society).

It is important to notice that there is no inherent order within these dimensions. It could be argued that without technical feasibility there is no such thing as viability or social acceptance. Thus, dimension 1, the adjacent possible is often considered the breeding ground of innovation. Successful innovations, however, only occur if there is an intersection among the boundaries of possibility within all three dimensions. This overlap can be initiated by changes in every single dimension. If, for instance, sequencing an entire personal DNA in order to develop personalized medication is technically possible and it is socially acceptable to get personal DNA sequenced, then innovation in this area is a function of the economic viability of DNA sequencing. Likewise, social developments might spur research in certain technical areas, which lead to an expanded adjacent feasible or adjacent viable as a result.

\section{Dimension 1: adjacent possible (technology)}

In our connected world, inventors stand on the shoulders of giants. The accelerated development of technology in the past century is a result of the increasing body of knowledge, continuously amassed by researchers around the world, and increasingly made available to others by the use of modern communication tools. As a well-known example take the development of the transistor in 1947, which consequently enabled the development of the integrated circuit in 1958, which in turn led to development of what we now know as modern computing. The invention of computers enabled software as a new field of further development and created the founding basis for the internet. In the internet domain, the invention of html and later Java led to the development of flash video with enabled Chad Hurley, Steve Chen, and Jawed Karim to start their video sharing platform YouTube in 2005. From a backward perspective, every single step of this development was crucial for the invention of YouTube. However, other paths may have led to different outcomes of what we know now as video sharing.

The basic mechanic, however, is quite simple. Each new technology opens the adjacent possible for new technologies based on this and all other available technologies. Each invention is based on preceding innovations which are in turn build on their predecessors. The adjacent possible can thus be described as a thin layer at the edge of current knowledge, which attracts new inventions and thus grows the body of exiting knowledge. 
Figure 1 visualizes the basic conception of the adjacent possible form a technology perspective. Where $\mathrm{A}^{1}$ represents a first innovation, e.g. the transistor, which consequently enables various technologies $B^{1}$ to $B^{n}$. These innovations, in turn, enable subsequently innovations $C^{1}$ to $C^{n}$. The adjacent possible represents the current edge of this process, which is comprised of all possible first-order combinations of existing technology $A^{1}$ to $E^{n}$.

\section{Dimension 2: adjacent viable (economy)}

If a technology or idea is within the adjacent possible, it can theoretically be realized. Whether it can be realized in reality depends on the economic viability of its realization concept. While it is currently theoretically possible to get your entire personal DNA sequenced in order to receive personalized medication, it is currently not economical feasible to do so. The sequencing of the first human genome costed in excess of US\$3 billion and took 13 years to complete (Hayden 2014). However, due to advances in the field of genomics over the past quarter-century, substantial reductions in the cost of genome sequencing were achieved. The current costs for decoding the human genome are expected to shrink below US\$1000 soon (Hayden 2014). Therefore, personal genome-based medication-as well as other related innovations-is gradually becoming economically feasible. As a result, we will see a lot of innovation based on sequenced personal DNA in the next years. We can describe the area of innovation development based on gradually emerging economic feasibility as a related form of the adjacent possible. Rather than becoming technically feasible, however, the trigger for innovation development here is the viability of its realization. The adjacent feasible defines an area of expected cost reduction for realization in a defined (future) time frame. It, again, creates a sphere of opportunity, attracting the rapid development of innovations in this field.

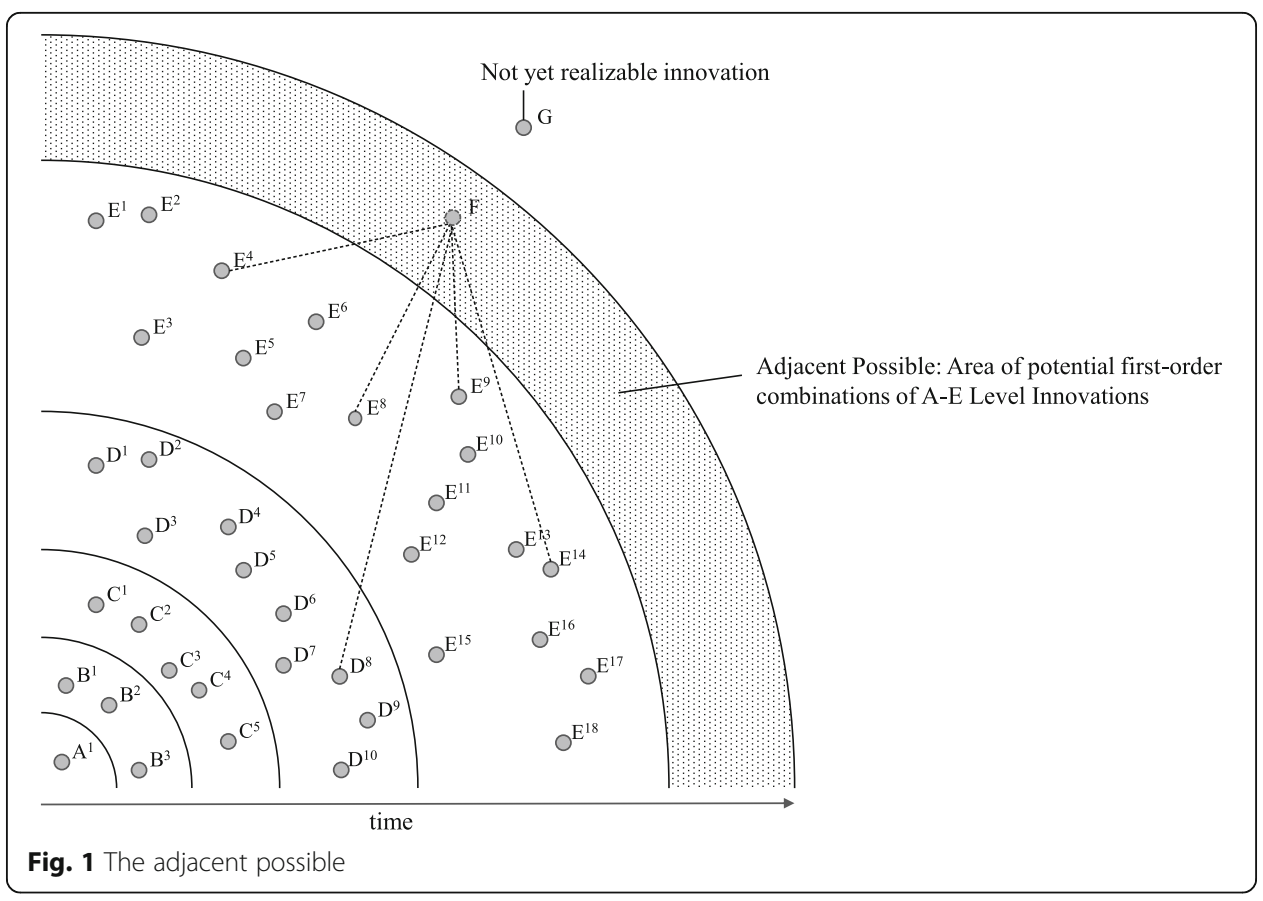


Extensive empirical research exists on the cost reduction of technology over time (Nagy et al. 2013). The most well known is certainly Moore's law (1965), which postulates that the number of transistors on a chip should double in each technology generation resulting in a linear cost decrease over time. Because of the accuracy with which Moore's law has predicted the cost reduction in semiconductors, similar studies have since been conducted on related industries from online commerce to genetic modifications (Mack 2011; Schaller 1997).

The underlying mechanic of this model is that the adjacent viable defines an area of potential innovation, based on an expected increase in viability within a defined time frame. The expected increase in viability can be of one technology-as in the example of genomic sequencing-but could also include multiple technologies. Figure 2 explains the basic mechanic of this model.

As an example, take the cost of digital storage and bandwidth for the realization potential of YouTube. Let A1 be the cost of data storage in 1998 at US $\$ 100$ per gigabyte, which gradually decreased to $A^{5}$ in 2005 at US $\$ 1$. The cost of upload/download bandwidth decreased similarly from $B^{1}$ in 1998 at US $\$ 1200$ per gigabit to $B^{5}$ in 2005 at US $\$ 75$ per gigabit. $A^{5}$ and $\mathrm{B}^{5}$ together enabled point $\mathrm{F}-$ The possibility to create an online video sharing platform like YouTube. The important point is that it was actually not viable, yet, to provide such a service in 2005. The income of advertising-even at today's income rates-would not have been enough to compensate storage and especially bandwidth costs. But since both costs were expected to further decline, it created an opportunity vacuum for those who foresaw the future development of viability in this technological context. It is also important to note that innovations outside this trajectory are doomed to fail. If, for instance, YouTube would have tried to build the same service 5 years earlier, it would have been outright impossible due to the high bandwidth and storage costs, even if it would have been technically feasible.




Dimension 3: adjacent acceptable (society)

Changing people's customs is an even more delicate responsibility than surgery in many cases (Rogers 2003, p.436).

Human behavior plays an important, if not the most important, role in the innovation process. Classical economic theory argues for consumers being "homo oeconomicus", purely motivated by rational considerations. It has become well known, however, that consumers are not always rational, objective, and utility-maximizing. Instead, they tend to base their decisions on other, more subjective, beliefs about a new technology (Fishbein and Ajzen 2010). Different areas of technological and service advancements have shown that reasonable innovations fail or take longer than expected to reach widespread acceptance, despite their proven usefulness (Rogers 2003; Story et al. 2011). This paradox is generally explained by consumer resistance to change learned behavior (Planing 2015).

Being one of the forefathers of sociology and social psychology, French lawyer Gabriel Tarde was the first to observe and analyze how new ideas flourished within French society at around 1900. In his influential book Laws of Imitation, Tarde (1903) dealt with the central question of compatibility: that is, the goodness of fit between the attributes of a diffusing item and the social and psychological attributes of the potential adopter. In his classic book Diffusion of Innovations, Everett Rogers (1962) developed a common framework for the social acceptance of the new ideas and concepts. Since then, the scope of innovation acceptance research has broadened as more and more disciplines became involved. Early studies mainly focused on rural sociology, investigating the spread of the new farming techniques, but soon scholarly interest tailed off somewhat to other disciplines such as communication, public health, and marketing. Since around 1990, the number of diffusion studies strongly increased, with many focusing on the rapid spread of the new communication technologies like the internet and mobile applications (Rogers 2003). The common result of these studies is that the diffusion process develops because potential customers do not adopt an innovation directly after it becomes available to them, but only with a-varying-time gap. Plotting the adoption of an innovation over time on a frequency basis will result in a normal, bell-shaped curve or-if the numbers of adopters are cumulated over time-in an S-Shaped curve of adoption (Rogers 2003). Figure 3 gives an overview of Roger's diffusion process.

By using some products repeatedly over a long period of time, consumers form habits and routines. In general, they aim to preserve these habits and strive for consistency and status quo rather than to continuously search for and embrace new behaviors (Bamberg et al. 2003; Bagozzi and Phillips 1982). If a new idea is not compatible with existing behavior, the perceived relative advantage of the new idea must be large enough to offset the perceived complexity of adopting to a new behavior. A theoretical model, frequently used for evaluating this relationship, is the Technology Acceptance Model (TAM) developed by Davis et al. (1989) The TAM is a tool for predicting and explaining user acceptance of an innovation and postulates that the acceptance decision can be reduced to two factors: the perceived usefulness (PU) and perceived ease of use (PEU). In essence, perceived ease-of-use (PEU) reduces uncertainty about the causeeffect relationship involved in the innovation's capacity to solve an individual's problem, while perceived usefulness (PU) describes the anticipated positive effect of using this technology. Bagozzi (2007, p.244) stated that more than 700 empirical applications of 


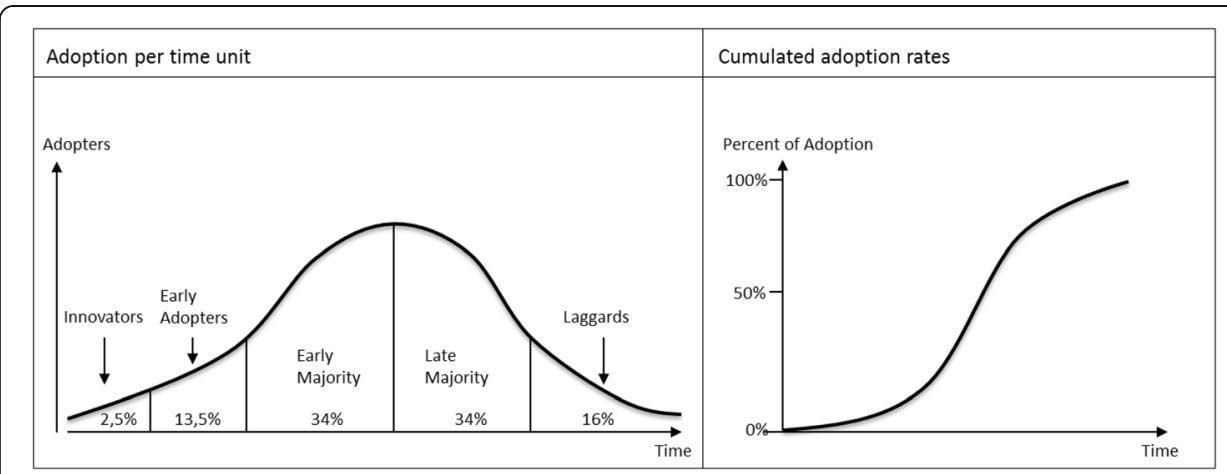

Fig. 3 Roger's diffusion process, source: own drawing based on Rogers (2003)

their original paper proved its validity for the adoption of different technologies. In particular, empirical research within this framework showed that both factors are heavily influence by the compatibility with existing beliefs and prior experience with comparable technologies (Karahanna et al. 2006, p.787).

Based on a meta-study of 1500 diffusion studies, Rogers (2003) developed a comparable framework for innovation adoption. The study showed that most of the variance in the rate of adoption of innovations, from 49 to $87 \%$, is explained by only five attribute categories: (1) relative advantage, (2) compatibility, (3) complexity, (4) trialability, and (5) observability (Rogers 2003, p.222). Changing from a combustion car to an electric car, for instance, requires a behavior change. The perceived advantages of electric driving need to offset the perceived disadvantages, i.e. perceived complexity and incompatibility with current driving and fueling patterns. If the observability is high, i.e. individuals can see others using electric cars and if it is easy to try the technology on a limited basis, the chances of adoption are higher.

We can conclude that consumer habits change over time according to an S-shaped curve of adoption and new technologies are the driver of change. It is important to note that the adoption time of new technologies has significantly decreased in the recent decades (Hohberger 2016; van den Bulte 2000). Thus, the stretch of S-shaped curves, on average, becomes shorter over time. While there is a multitude of factors that influence the adoption speed of new technologies, the compatibility with existing behavior and beliefs is the single most important driver for the acceptance of innovation (Bamberg et al. 2003). Along the lines of the adjacent possible, socially accepted behavior builds on the stack of currently diffused ideas and concepts. If compatibility with existing behavioral patterns is too small, it is almost impossible to initiate social change immediately. Rather, gradual steps need to be taken. Using a fully autonomous vehicle, for instance, is out of the accepted behavior range for most people. Yet, by the increasing use of driver-assistance systems, individuals will get more used to the idea of handing over driving control to a computer system. The adjacent acceptable thus represents a small area on the current edges of socially accepted behavior, which currently only innovators embrace but soon will reach the early majority of technology adopters. Figure 4 shows the resulting conceptual model of the adjacent acceptable.

As an example for adjacent acceptable consider the diffusion of video streaming. Watching movies online was a behavior that was unheard of in 2005 when YouTube started. After 10 years of watching short video clips on YouTube, it became more 


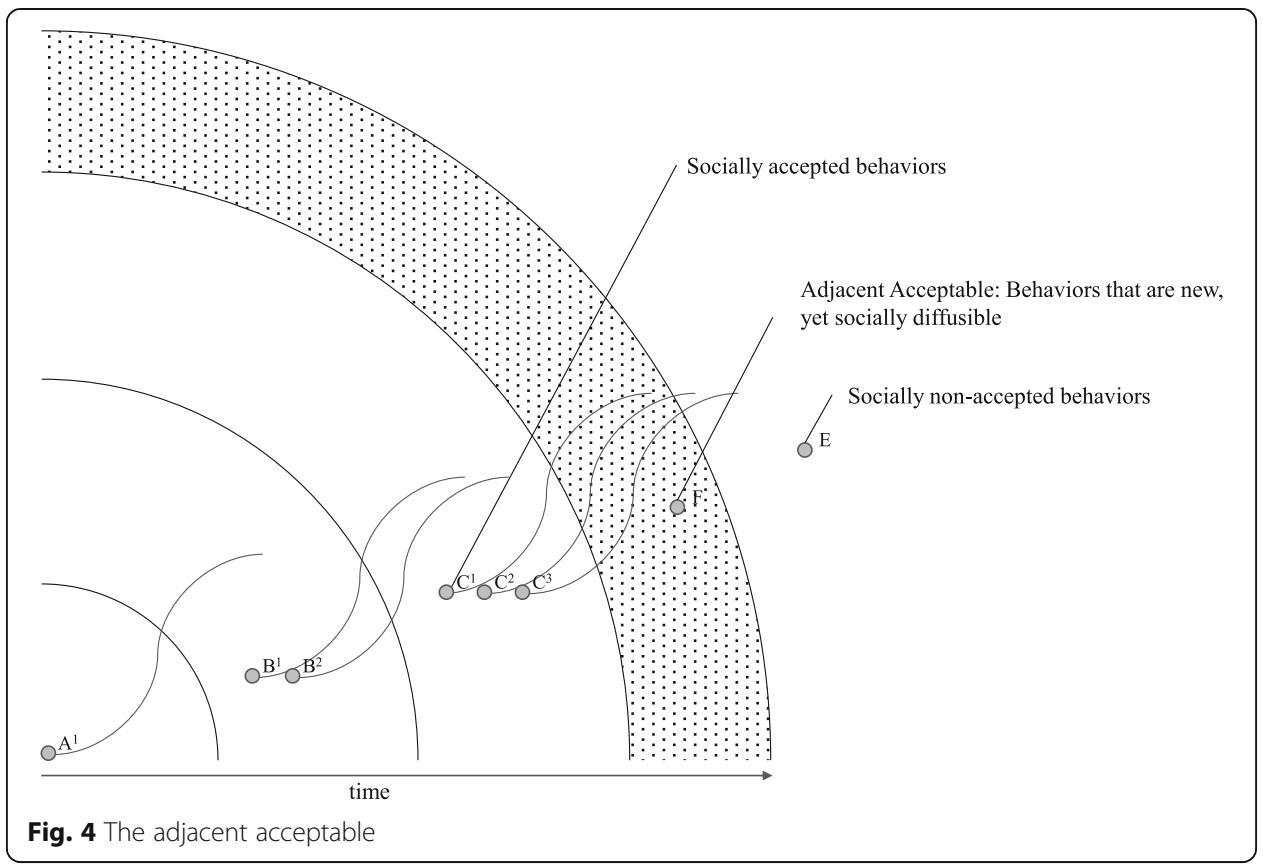

natural to most people to use the internet as a channel for TV movies and series. Watching movies online reached the early majority on the S-shaped adoption curve. Other required behaviors became socially acceptable in parallel, most importantly paying online using PayPal and credit cards. This opened up the adjacent acceptable for offers like Netflix or Amazon Prime Video. In the visualized model, take the adoption of personal computers as $\mathrm{A}^{1}$. The full adoption of this technology was a prerequisite for the adoption of the internet access $\mathrm{B}^{1}$ and later high-speed internet $\mathrm{B}^{2}$. This was the prerequisite for wide-spread adoption of video streaming $\mathrm{C}^{1}$, online payment $\mathrm{C}^{2}$, and online Commerce $\mathrm{C}^{3}$, which brought payed, video-streaming (F) into the adjacent acceptable.

\section{The opportunity vacuum}

We have seen that the occurrence of innovations, despite its randomness, follows certain patterns and generally occurs within the defined boundaries of the adjacent possible, the adjacent viable and the adjacent acceptable. It is only, however, by bringing all three dimensions together, that we can really explain the origin of innovations. In retrospective, the origin of every innovation can be pinpointed to a moment when all three dimensions achieved an intersecting area. A moment, when it was technically feasible to realize an idea, financially viable to do so and when the early majority of the society was ready to adopt the idea. Figure 5 shows the combined three dimensions, with the intersecting area, which we refer to as the opportunity vacuum (OV).

The intersecting area among all three dimensions at a given point of time yields a flow of emergent possibilities which enable innovation to emerge. While the area itself can neither be measured nor described in detail, the emergent innovations can be traced with a relatively high accuracy in retrospective. The occurrence of a new idea within the adjacent possible can be attributed to its preceding ideas it was built upon. 


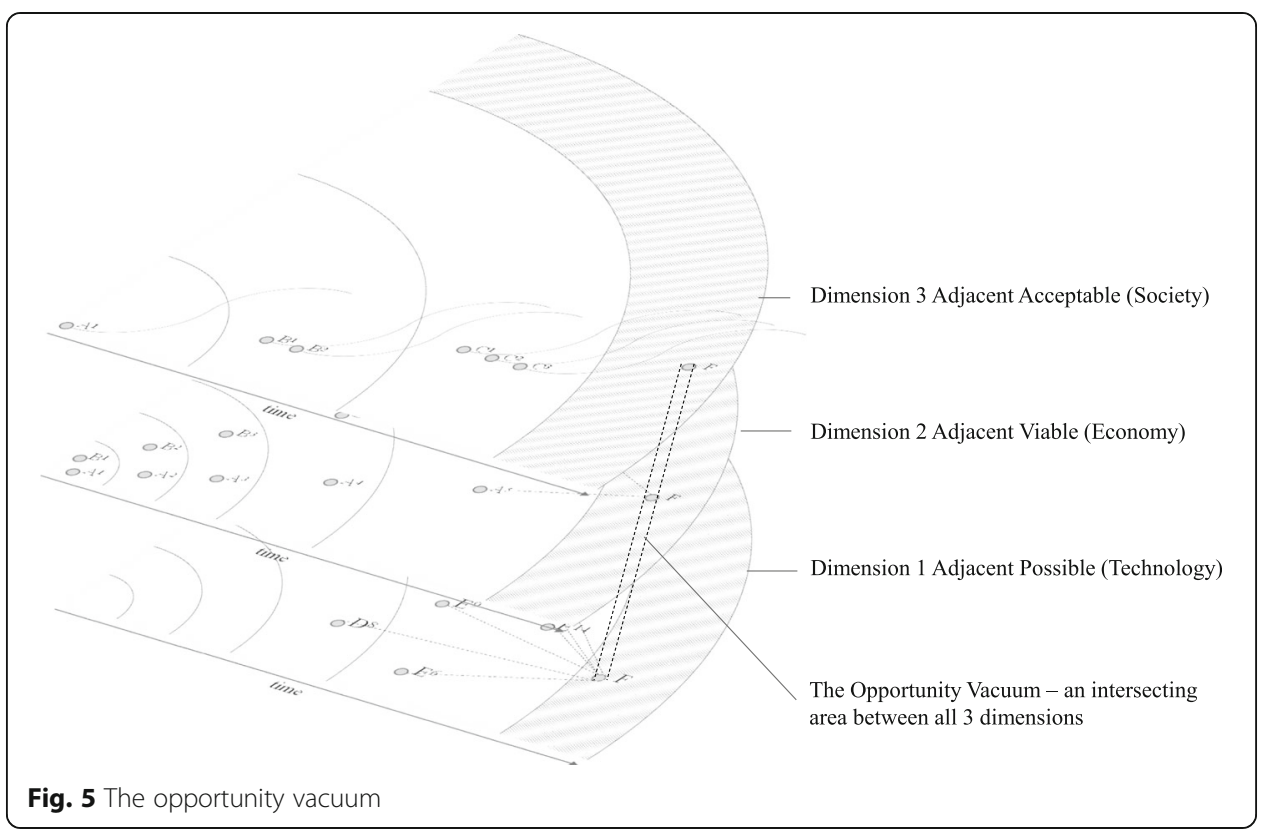

The economic resources needed for the realization of an idea within the adjacent viable can be measured over time as they approached a viable level for realization and exploitation. The adoption curve of technologies within the adjacent acceptable, finally, can be traced with increasing accuracy, mainly due to new communication tools and connectivity of products. In hindsight, we are thus capable of explaining how an innovation has evolved throughout this model with relatively high precision.

\section{Application of the OV framework to predict future economic novelty}

The OV framework is a valid method for explaining the origin of innovations in retrospective. Whether the model could also be used to predict future occurrence of innovation by defining the area of the OV and, in particular, its boundaries, however, is a more complex question. Considering the first dimension, the adjacent possible, Felin et al. (2014) compare the problem to the myriad functionalities and uses of any technological object, which cannot be prestated or captured. A simple technology, such as an electrical engine, can theoretically be applied to myriad uses which are both indefinite and unadorable, since most would not provide any value. A prediction of where the development of an electric engine will lead us is thus not feasible, since it is simply not possible, a priori, to list the number of uses of an electric engine. As a result, no full account or set of algorithms can be given about all possible, actions, uses, and functions of an electric engine. This algorithmic incapacity to compute developments with the adjacent possible does not mean that the adjacent possible defies any explanation. Other than in Newtonian and Laplacian physics, we cannot determine and predict motion or direction in the first dimensions of this model. Nonetheless, the evolution of new technologies is not fully random. Its randomness is canalized within the sphere of the adjacent possible. The set of adjacent possible directions is extremely large but not infinite. While we cannot predict the exact development of the future technically feasible, we can predict the area of where future technology will become feasible. 
In order to apply the OV framework to predict future innovation, we therefore use an example, which currently enjoys high attention by the scientific as well as practitioner community: autonomous, electrical multicopters aimed at passenger transportation. Experts argue that these systems, often called passenger drones, will enable individual sky transport in the near future (see Lidynia, Philipsen, and Ziefle 2017). While we cannot predict how the development of passenger drones will exactly happen, we can use the model to derive an idea in which direction the development will go and where an opportunity for innovation will occur. Let us consider at the adjacent possible first. First prototypes based on either electric drones with multiple rotors were already presented to the public. However, technically, there are some major restrictions. The development of a passenger drone would require certain technology breakthroughs; first, more efficient battery technology. In order to increase the currently around 20min flight time to about $2 \mathrm{~h}$ without adding weight (which would reduce flight time again), would require battery efficiency to increase drastically. Experts predict that the specific energy of current conventional lithiom-ion batteries, which is around $150 \mathrm{Wh} /$ $\mathrm{kg}$, needs to be brought to around $1.800 \mathrm{Wh} / \mathrm{kg}$ (National Academies of Sciences, Engineering, and Medicine 2016). At the same time, cognitive computing needs to improve as well. In order to enable fully autonomous flight, these systems need to combine visual data with other sensors, such as RADAR and LIDAR. This will be a prerequisite for navigating safely and efficiently through the air, based on real-time sensor data (Valavanis and Vachtsevanos 2014). While we cannot predict the boundaries of the adjacent possible dimension exactly, we can nonetheless conclude that currently at least two major building blocks are missing: more efficient battery technology and improved cognitive computing systems, who enable fully autonomous flying.

In the next step, the adjacent viable is considered. While it is already possible to buy a private helicopter, significant cost reduction will be a prerequisite to make individual sky transport a mass-market phenomenon. Passenger drones provide the opportunity to make that fundamental shift. The main factor in this regard will be the cost of electric energy storage, or in other words, the battery prices. Current battery costs in electric cars are $\sim$ US $\$ 150$ to $\sim$ US $\$ 200$ per kilowatt-hour, making them the most cost efficient battery products, well below the industry average pack costs of $\sim$ US\$350 per kilowatt-hour. In order to make flying passenger drones a viable business, we need to see these prices drop to somewhere around US $\$ 20$ per kilowatt-hour (Henbest et al. 2015). Based on the historical cost developments, a prediction could be derived, when this point could be reached.

Finally, the adjacent acceptable dimension is considered. This new form of mobility is far off anything consumers have experienced in the past and will require a substantial behavior change. As with any other new technologies, we will see an S-Shaped curve of technology diffusion, with a slow incline in the first years of availability. At first it will be only the innovators and early adopters, who are ready to accept the non-perfect product in terms of range, conform, and maybe even safety. The early majority (the part of the mass market more open to innovation) is pragmatic, in the sense that they will wait for the technology to proof its benefits and safety. Therefore, we can expect that once technological possibility and economic viability are reached, it will take several years of proof of concept before the early majority of customers will be ready to go on-board. Once this happens, however, diffusion theory predicts an exponential 
acceptance rate increase, which would mean that the technology could potentially conquer the world in only a couple of years.

There is no opportunity vacuum for passenger drones, yet. However, we can see developments in all three dimensions that could potentially lead to the rise of an OV in the next couple of years. For a technology expert, or anyone interested in either starting a business or investing in a business in this area, it is therefore wisely to monitor closely the developments in each of the three dimensions. From a scientific point of view, the framework enables to make a prediction about the rise of the OV, which could in a longitudinal study be checked against reality.

In sum, the OV is aimed at describing the origin of innovations in retrospective. It does not provide an exact solution for the prediction of future economic novelty, since there is no algorithmic way to specify the yet "empty" set of possibilities that are adjacent to the existing phase spaces. However, the framing approach along the three dimensions of the OV provides a reliable method to evaluate known paths of innovation. Once the path is known, e.g. the technology is within the adjacent possible of dimension 1 , the OV framework can be used to predict where future entrepreneurial activity is likely to occur.

\section{Conclusions}

The OV framework transfers the logic of the innovation system (IS) approach to the microeconomic level. While the IS framework can help identify a network knowledge flow by analyzing the interactions among stakeholders on a macro level, the OV framework explains the origins of innovations as a constellation of processes on three different dimensions on a micro level. It thereby delivers a model for the emergence of innovations among individual actors and provides a method to explain and, to some extent, also to predict the origin of innovations.

This microeconomic perspective counters common misconceptions. Innovations are neither rooted in serendipitous moments of individual genius, nor in mystical sudden enlightments. In reality, they are based on a close match of the right circumstances in three different dimensions. There might be a form of serendipity involved, a lucky moment in which the connection of the right hunches happens almost magically. Yet, there are strict boundaries of where and how this can happen, as it only occurs within the adjacent possible, the adjacent viable, and the adjacent acceptable. It is the moment when all three dimensions achieve an intersecting area, when the opportunity vacuum is created. The OV is a space, which strongly attracts innovation, often leading to multiple inventions emerging independently at the same time. This OV framework therefore helps to demystify the origin of innovations by delivering an explanation of the phenomenon of multiple independent inventions and by explaining how innovations emerge in general. The OV, however, does not only allow for an explanation of the origin of innovations in retrospective. By understanding the transformation of the dimensions, the model allows to anticipate where future innovations will occur. While there is a convincing argument that a computational approach for predicting future entrepreneurial activity along dimension 1 is not practicable, the OV still provides a prediction tool, based on framing activity along dimensions 2 and 3. The quality of these predictions will depend on a most precise measurement of the current state of each trajectory but also on an incorporation of different prediction techniques. 


\section{Limitations of the proposed research model}

It is important to acknowledge some major limitations regarding the OV framework.

First, the focus of this framework is the micro dimension, meaning that the process of innovation on a macroeconomic level, which involves the flow of information in more complex systems, such as formal or informal networks, is not in the scope of this model. Consequently, the influence of institutional policy intervention in relation to the changes in innovation behavior cannot be explained by this model.

Second, the OV framework does not provide an exact solution for the prediction of future economic novelty. The development of the three dimensions is far from uniformly continuous radial growth, as the figures suggests. Rather the edges of current knowledge, viability, and social acceptability are fringed and fuzzy. The transformation is erratic in nature, often including leapfrog developments while other parts may stay rather static for decades. Consequently, the overlapping OV area constantly evolves and changes its surface area, attracting innovations to different parts of technical and societal development. The quality of predictions thus relies on most exact framing along the dimensions of this model. While the model is an adequate method for explaining the origin of innovations in retrospective, its predictive capabilities are limited in this regard.

\section{Recommendations for future research}

The major challenge is to apply the OV model to real life innovations and to develop a reliable measurement of each dimension. Future research should therefore focus not only on a measurement of the individual dimensions, but also on a combined approach. There is a considerable amount of empirical research on economic viability, as well as on social diffusion of innovations. The challenge is to combine these techniques and apply them as a framing method on top of the adjacent possible. In particular, it would be interesting to better understand the interrelation of the dimensions and to see what happens to the other dimensions if one dimension demonstrates accelerated changes. It is important to notice that the speed of development has increased drastically on all three dimensions in recent years. In the social dimension, for instance, increased communication speed has led to a decreased adoption time of new technologies-from 20 years for color TVs to a few days for new apps such as Pokémon Go. Applying the model to current innovation would provide an explanation how these accelerated developments translated into developments in the three dimensions and eventually led to the development of each specific innovation in retrospective.

This will enable us to develop a better understanding not only on how innovations origin and evolve but might also help us to understand how future innovations will unfold.

\footnotetext{
Competing interests

The author declares that he has no competing interests.

Received: 29 September 2016 Accepted: 13 January 2017

Published online: 07 March 2017

References

Adams, R., Bessant, J., \& Phelps, R. (2006). Innovation management measurement: a review. International Journal of Management Reviews, 8(1), 21-47.

Alvarez, S. A., Barney, J. B., \& Anderson, P. (2013). Forming and exploiting opportunities: the implications of discovery and creation processes for entrepreneurial and organizational research. Organization Science, 24(1), 301-317.

Arrow, K. (1962). Economic welfare and the allocation of resources for invention. In The rate and direction of inventive activity: economic and social factors (pp. 609-626). Princeton, NJ: Princeton University Press.
} 
Bagozzi, R., \& Phillips, L. (1982). Representing and testing organizational theories, a holistic construal. Administrative Science Quarterly, 27(3), 459-489.

Bagozzi, R. P. (2007). The legacy of the technology acceptance model and a proposal for a paradigm shift. Journal of The Association For Information Systems, 8(4), 244-254.

Bamberg, S., Ajzen, I., \& Schmidt, P. (2003). Choice of travel mode in the theory of planned behavior: the roles of past behavior, habit, and reasoned action. Basic and Applied Social Psychology, 25(3), 175-187.

Baregheh, A., Rowley, J., \& Sambrook, S. (2009). Towards a multidisciplinary definition of innovation. Management Decision, 47(8), 1323-1339.

Berkun, S. (2010). The myths of innovation. Beijing: O'Reilly.

Boden, M. A. (2004). The creative mind: myths and mechanisms. Hove, UK: Psychology Press.

Carayannis, E. G., Barth, T. D., \& Campbell, D. F. (2012). The Quintuple Helix innovation model: global warming as a challenge and driver for innovation. Journal of Innovation and Entrepreneurship, 1(1), 1-12.

Carayannis, E. G., \& Campbell, D. F. (2009). 'Mode 3' and 'Quadruple Helix': toward a 21st century fractal innovation ecosystem. International Journal of Technology Management, 46(3-4), 201-234.

Christensen, C. (1997). The innovator's dilemma: when new technologies cause great firms to fail. Boston, MA: Harvard Business School Press.

Coccia, M. (2005). Measuring intensity of technological change: the seismic approach. Technological Forecasting and Social Change, 72(2), 117-144.

Csikszentmihalyi, M. (2014). Society, culture, and person: a systems view of creativity. Dordrecht, Netherlands: Springer.

Davis, F. D., Bagozzi, R. P., \& Warshaw, P. R. (1989). User acceptance of computer technology: a comparison of two theoretical models. Management Science, 35, 982-1003.

Eckhardt, J. T., \& Shane, S. A. (2013). Response to the commentaries: the individual-opportunity (IO) nexus integrates objective and subjective aspects of entrepreneurship. Academy of Management Review, 38(1), 160-163.

Edquist, C. \& Hommen, L. (1999). Systems of innovation: theory and policy for the demand side. Technology in society, 21(1), 63-79.

Etzkowitz, H., \& Leydesdorff, L. (2000). The dynamics of innovation: from National Systems and "Mode 2" to a Triple Helix of university-industry-government relations. Research policy, 29(2), 109-123.

Felin, T., Kauffman, S., Koppl, R., \& Longo, G. (2014). Economic opportunity and evolution: beyond landscapes and bounded rationality. Strategic Entrepreneurship Journal, 8(4), 269-282.

Fishbein, M., \& Ajzen, I. (2010). Predicting and changing behavior. the reasoned action approach. New York: Psychology Press.

Freeman, C. (1987). Technology policy and economic performance: lessons from Japan. London: Pinter.

Freeman, C. (1994). The economics of technical change. Cambridge journal of economics, 18(5), 463-514.

Gault, F. (2012). User innovation and the market. Science and Public Policy, 39(1), 118-128.

Goldberg, J., Horowitz, R., Levav, A., Mazursky, D. (2003). Finding your innovation sweet spot. Harvard Business Review, March 2013 Issue

Hall, A. (2005). Capacity development for agricultural biotechnology in developing countries: an innovation systems view of what it is and how to develop it. Journal of international development, 17(5), 611-630.

Hayden, E. C. (2014). Technology: the \$1,000 genome. Nature, 507(7492), 294-295.

Henbest, S., Giannakopoulou, E., \& Cuming, V. (2015). New energy outlook: long-term projections of the global energy sector. New York: Bloomberg Finance.

Hekkert, M. P., Suurs, R. A., Negro, S. O., Kuhlmann, S., \& Smits, R. E. (2007). Functions of innovation systems: a new approach for analysing technological change. Technological forecasting and social change, 74(4), 413-432.

Hohberger, J. (2016). Diffusion of science-based inventions. Technological Forecasting and Social Change, 104(2016), 66-77.

lizuka, M. (2013). Innovation systems framework: still useful in the new global context? UNU-MERIT Working Papers. 2013-005.

Johnson, S. (2010). Where good ideas come from: the natural history of innovation. New York: Riverhead Books.

Kaplan, J. M., \& Warren, A. C. (2010). Patterns of entrepreneurship management. Hoboken, NJ: Wiley.

Karahanna, E., Agarwal, R., \& Angst, C. M. (2006). Reconceptualizing compatibility beliefs in technology acceptance research. MIS Quarterly, 30(4), 781-804.

Kauffman, S., \& Levin, S. (1987). Towards a general theory of adaptive walks on rugged landscapes. Journal of theoretical Biology, 128(1), 11-45.

Kauffman, S. A. (2002). Investigations. Oxford: Oxford University Press.

Kline, S. J., \& Rosenberg, N. (1986). An overview of innovation. In R. Landau (Ed.), The positive sum strategy: harnessing technology for economic growth (pp. 275-304). Washington: National Academy Press.

"List of multiple discoveries" Wikipedia: Wikimedia Foundation, Inc. 16 Sep. 2016. Web. 18 Sep. 2016. [https://en. wikipedia.org/wiki/List_of_multiple_discoveries]

Lundvall, B. A. (1992). National innovation systems: towards a theory of innovation and interactive learning. London: Pinter.

Lidynia, C., Philipsen, R., \& Ziefle, M. (2017). Droning on about drones-acceptance of and perceived barriers to drones in civil usage contexts. In Advances in Human Factors in Robots and Unmanned Systems (pp. 317-329). New York: Springer International Publishing.

Mack, C. A. (2011). Fifty years of Moore's law. IEEE Transactions on semiconductor manufacturing, 24(2), 202-207.

Merton, R. K. (1961). Singletons and multiples in scientific discovery: a chapter in the sociology of science. Proceedings of the American Philosophical Society, 105(5), 470-486.

Metcalfe, S. (1988). The diffusion of innovations: an interpretative survey. In Technology and economic theory (pp. 560-589). London: Pinter.

Mitleton-Kelly, E. (2003). Ten principles of complexity and enabling infrastructures. In Complex systems and evolutionary perspectives on organisations: the application of complexity theory to organisations (pp. 23-50). Amsterdam: Pergamon.

Moore, G. E. (1965). Cramming More Components onto Integrated Circuits. Electronics Magazine, 38(8), 114-117.

Nagy, B., Farmer, J. D., Bui, Q. M. \& Trancik, J. E. (2013). Statistical basis for predicting technological progress. PloS one, $8(2)$, e52669. 
National Academies of Sciences, Engineering, and Medicine. (2016). Commercial aircraft propulsion and energy systems research: reducing global carbon emissions. Washington: The National Academies Press.

Nelson, R., \& Winter, G. W. (1982). An evolutionary theory of economic change. Cambridge: Belknap/Harvard University Press.

Ogburn, W. F., \& Thomas, D. (1922). Are inventions inevitable? A note on social evolution. Political Science Quarterly, $37(1), 83-98$.

Planing, P. (2015). Measuring consumer innovativeness: an empirical re-evaluation of Roger's innovativeness scale. International Journal of Sales, Retailing and Marketing, 2(4), 86-96.

Rifkin, J., \& Howard, T. (1981). Entropy: a new world view. New York: Bantam Books.

Ranga, M., \& Etzkowitz, H. (2013). Triple Helix systems: an analytical framework for innovation policy and practice in the Knowledge Society. Industry and Higher Education, 27(4), 237-262.

Roberts, R. M. (1989). Serendipity: accidental discoveries in science. New York: Wiley Science Editions. Serendipity: Accidental discoveries in science.

Rogers, E. M. (1962). Diffusion of innovations. New York: The Free Press.

Rogers, E. M. (2003). Diffusion of innovations. New York: The Free Press.

Schaller, R. R. (1997). Moore's law: past, present and future. IEEE spectrum, 34(6), 52-59.

Story, V., O'Malley, L., \& Hart, S. (2011). Roles, role performance, and radical innovation competences. Industrial Marketing Management, 40, 952-966.

Tarde, G. (1903). The laws of imitation. New York: H. Holt and Company.

Tacer, B., \& Ruzzier, M. (2015). User-driven innovation: an exploratory study. Economic and Business Review for Central and South-Eastern Europe, 17(1), 69-92.

Trott, P. (2010). Innovation management and new product development. Harlow: Financial Times Prentice Hall.

"Vacuum" Merriam-Webster Dictionary. (2004) New York: Merriam-Webster. Merriam-Webster.com. Web. 14 Sep. 2016

Van den Bulte, C. (2000). New product diffusion acceleration: measurement and analysis. Marketing Science, 19(4), 366-380.

Valavanis, K. P., \& Vachtsevanos, G. J. (2014). Handbook of unmanned aerial vehicles. New York: Springer Publishing Company, Incorporated.

White, M. A., \& Bruton, G. D. (2011). The management of technology and innovation. A strategic approach. Mason: South-Western Cengage Learning.

Winter, S. G. (2012). Purpose and progress in the theory of strategy: comments on Gavetti. Organization Science, 23(1), $288-297$.

Zawislak, P. A. A., Alves, A. C., Gamarra, J. E. T., Barbieux, D., Reichert, F. M. (2011). Innovation capabilities of the firm: The Brazilian experience. In: Proceedings of the 9th Globelics International Conference, November, 2011, Buenos Aires. http://inspercom.org/wp-content/uploads/2014/02/2011_INNOVATION-CAPABILITIES-OF-THE-FIRM_-THEBRAZILIAN.pdf

\section{Submit your manuscript to a SpringerOpen ${ }^{\circ}$} journal and benefit from:

- Convenient online submission

- Rigorous peer review

- Immediate publication on acceptance

- Open access: articles freely available online

- High visibility within the field

- Retaining the copyright to your article

Submit your next manuscript at $>$ springeropen.com 